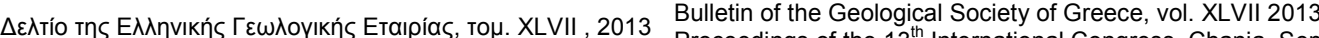
Proceedings of the $13^{\text {th }}$ International Congress, Chania, Sept.

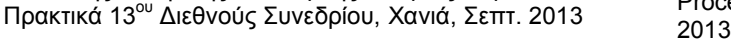

\title{
RESULTS FOR THE SHALLOW STRUCTURE OF THE BROADER REGION OF CHANIA BY HVSR MEASUREMENTS OF AMBIENT NOISE AND THEIR VALIDATION USING SIMULATION OF AMBIENT NOISE AND INDEPENDENT GEOLOGICAL INFORMATION
}

\author{
Papadopoulos I. ${ }^{1}$, Papazachos C. $^{2}$, Savvaidis A. ${ }^{3}$, Theodoulidis N. ${ }^{3}$, \\ Vallianatos $F^{1}{ }^{1}$ and Tsourlos $P^{2}{ }^{2}$ \\ ${ }^{I}$ Technological Institute of Crete, Department of Natural Resources and Environment, \\ ilias@chania.teicrete.gr,fvallian@chania.teicrete.gr \\ ${ }^{2}$ Aristotle University of Thessaloniki, Department of Geology,kpapaza@geo.auh.gr, \\ tsourlos@geo.auth.gr \\ ${ }^{3}$ Institute of Engineering Seismology and EarthquakeEngineering, alekos@itsak.gr, \\ ntheo@itsak.gr
}

\begin{abstract}
The city of Chania is located at the Western-North part of the island of Crete. It is mostly built over Neogene sediments of unknown thickness. In the southern part of the city the Chania basin is developed, filled mainly by Quaternary deposits overlying the deep Neogene sediments. In this complex geological setting, we conducted over 200 single station measurements of ambient noise, aiming to estimate the predominant frequency of the subsurface formations. The obtained results for the HVSR data show a different behavior between sites located on Neogene and Quaternary deposits. In general, Neogene sediments show a single peak at low frequencies (below $1 \mathrm{~Hz}$, typically in the range $0.4-0.6 \mathrm{~Hz}$ ), indicating a very thick layer overlying the bedrock (Trypalion and Plattenkalk limestones). On the other hand, measurements at Quaternary deposits show two peaks, with the first one similar to the Neogene formations, while the second one is identified at higher frequencies, typically 0.8-4.0 Hz. Simulation of ambient noise 1-D models show a good correlation between the experimental and theoretical HVSR curves, especially when the initial model consists of two layers (typically Neogene sediments overlying high-velocity bedrock formations) with a clear identification of the lower frequency HVSR peak, while for three layered models (typically Quaternary sediments and underlying softer Neogene and Neogene/bedrock high-velocity formations) results are more complicated, although both HVSR frequencies can be partly reconstructed.
\end{abstract}

Key words: Microtremor, Resonance frequency, Site effects.

\section{Пєрі́ $\eta \psi \eta$}

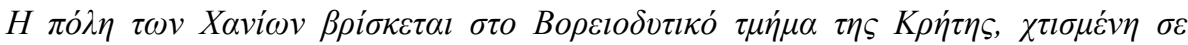

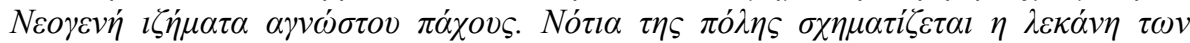

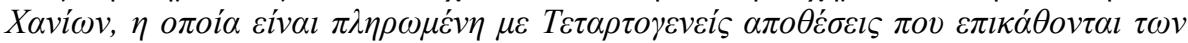

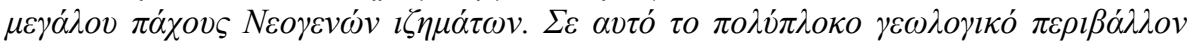




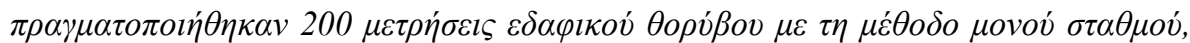

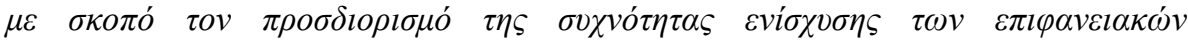

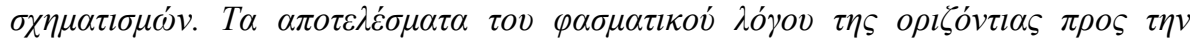

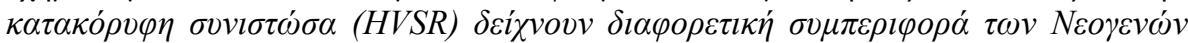

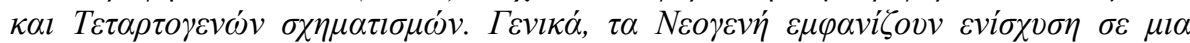

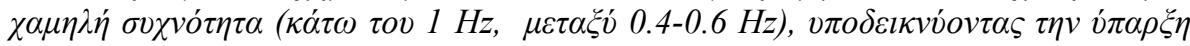

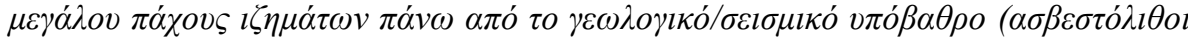

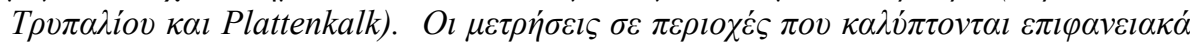

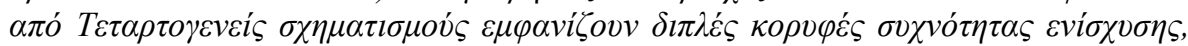

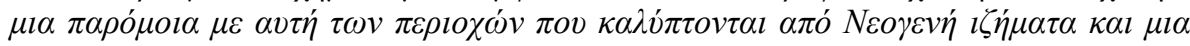

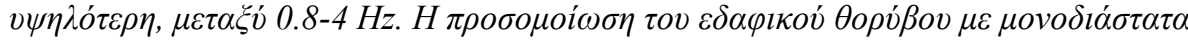

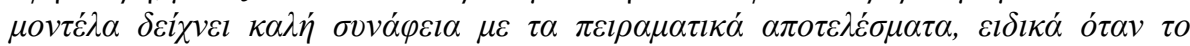

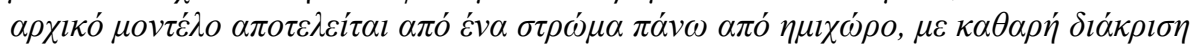

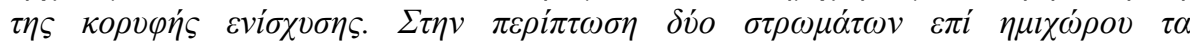

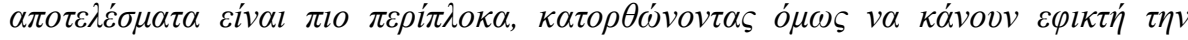

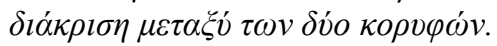

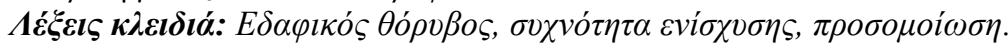

\section{Introduction}

Amplification of earthquake ground motion due to the effect of local geological site conditions (e.g. thick sedimentary deposits) is an important factor when determining the seismic risk of areas not located on bedrock formations. Determining the ground response of different geological formations with traditional methods is not an easy task, especially in urban areas (e.g. due to anthropogenic factors) or when a large area needs to be covered in high density. During the past decades the usage of ambient noise recordings has been extensively employed as a tool to determine the eigenfrequency of sedimentary formations due to seismic excitation and possibly their lower level of expected amplification. The most common approach is the calculation of spectral ratio of horizontal to vertical component of ambient noise-HVSR (Nakamura, 1989), despite the lack of a rigorous theoretical basis (Bard, 1999). In the present study 200 measurements of ambient noise with a single recording station have been performed in the urban area of Chania and its southern basin in order to determine the eiganfrequency of excitation. Measurements are grouped based on the spatial similarity of the HVSR curve in order to define common properties of the geological formations. Using Hisada's method for the calculation of Green function (Hisada, 1994, 1995), five (5) groups of measurements have been simulated using a 1-D model. The simulation of ambient noise sources has been performed by the use of the RANSOURCE algorithm (Moczo and Kristek, 2002).

\section{Geological Setting and Experiment Setup}

\subsection{Geological Setting}

The broader study area consists, according to the available IGME geological map, of Tripalion and Plattenkalk limestones in the mountainous area south of the basin of Chania, Quaternary deposits filling the basin of Chania south of the main city complex and Neogene sediments filling the urban area at the North. Bastelli (2002) presented a more detailed description of the Neogene sediments covering the city of Chania. The largest part of the eastern and southern Chania city area is covered with alternations of white and grey marly limestones, marls and yellow marly limestones with thin layers of sandstone. The western section of the city region is covered with alluvial Quaternary deposits, while at the coast there are human deposits, medium thickness sand formations, as well as fluvial sediments. At the southwestern area we find compact marly limestone with colors rang- 
ing from white to grey, within which bioclastic limestone lenses can be found, along with marly gravels (Figure 1).

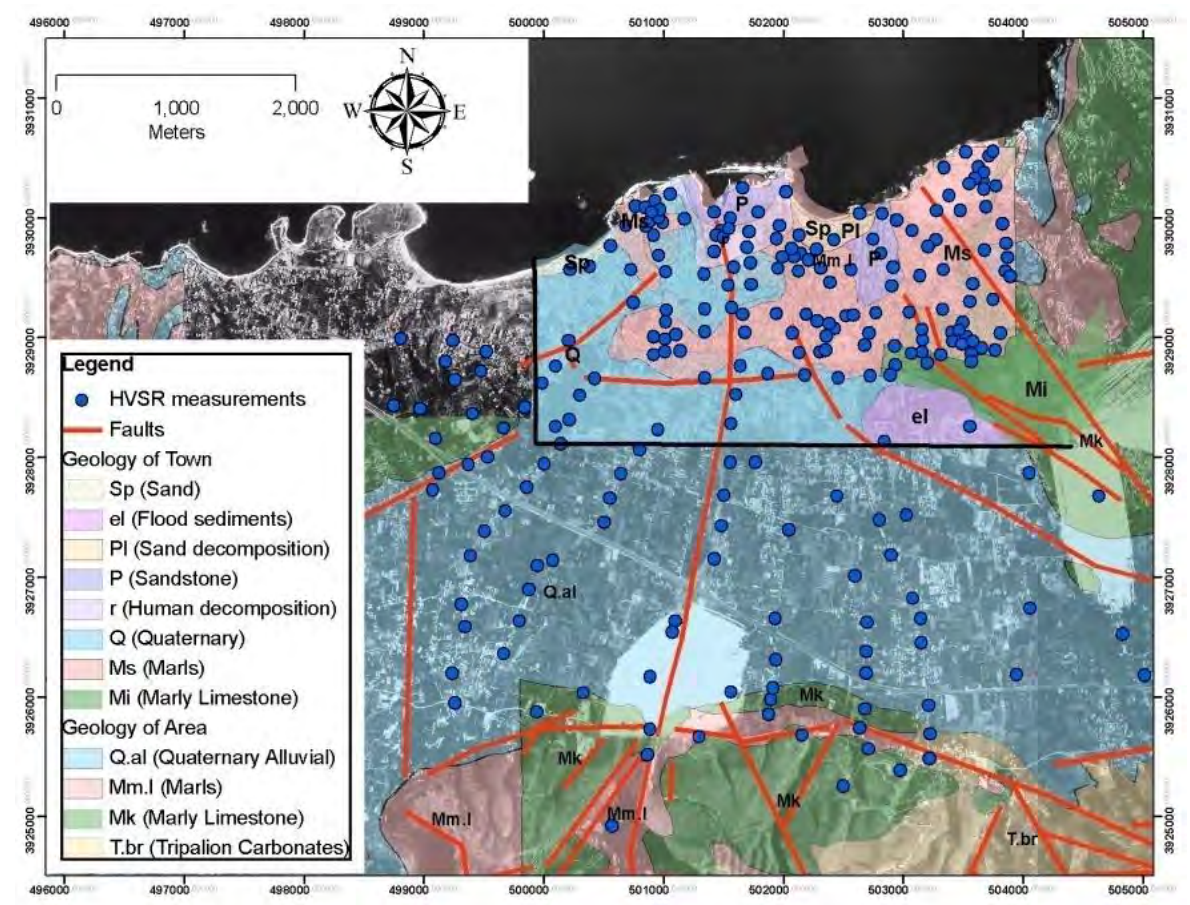

Figure 1 - Geological map of the broader Chania area (based on IGME map and Bastelli, 2002). The HVSR recording sites are also presented (blue dots).

\subsection{Experiment Setup}

The 200 measurements of ambient noise have been conducted in the broader area of interest, using a Lennarz 3D/5s sensor coupled with City Shark II digitizer. All measurements lasted 30 minutes and were obtained at night hours (typically 24:00-06:00) to minimize human and traffic noise influence. For all measurements a common processing approach was adopted, removing the mean value and filtering them with a bandpass Butterworth filter in the $0.2-20 \mathrm{~Hz}$ range, which corresponds to the main frequency window of interest. Measurements were split in smaller timewindows of 40 seconds length. The spectrum of each component's window was calculated using a Fast Fourier Transform (FFT) with tapering of 5\% and smoothed using the Konno-Ohmachi approach, with a $b$ constant of 40 (Konno and Ohmachi, 1998). The horizontal components were then geometrically averaged and divided with the vertical component to obtain the Horizontal to Vertical Spectral Ratio (HVSR) of each measurement. The lowest peak in frequency exceeding the amplitude value of 1.8-2.0 was chosen as the resonance frequency of sediments overlying the geological bedrock. If more than one peak was observed, we checked the spectrum of measurement to define whether its origin was human related, e.g. by observing spikes in the FFT spectrum at the same frequency. If the origin of peak was considered as of possible geological origin, then a second frequency was picked, following the same amplitude criteria as above.

Measurements were visually inspected in a GIS system and spatial distribution maps were created regarding the selected frequencies and amplitudes. Measurements were grouped based on the similarity of the corresponding HVSR curve in order to recognize patterns reflecting different geological formations. Using Hisada's method (Hisada, 1994, 1995) a calculation of the theoretical Green function was performed for 1-D geophysical models derived on the basis of independent geophysical (noise array) measurements (Papadopoulos, 2013). The usage of the RANSOURCE

XLVII, No $3-1203$ 
algorithm (Moczo and Kristek, 2002) provided the ambient noise input signal calculated for an area much similar in size to the study area.

\section{Theoretical Approach}

\subsection{Horizontal to Vertical Spectral Ratio}

Nogoshi and Igarashi (1970) presented the first usage of the HVSR of ambient noise for site response estimation, showing the relationship between the HVSR curve and the ellipticity curve of the Rayleigh waves around the fundamental resonance frequency. Nakamura (1989) showed that it is possible to estimate the resonance frequency of sediments, proposing that the ambient noise consists of S-waves, and showing that a good approximation of the amplification can be achieved, making HVSR a useful tool to reveal some of the dynamic characteristics of local site effects. Until today, the applicability of HVSR technique has been the subject of numerous studies around the World (e.g. Field and Jacob, 1995; Horike et al., 2001), and in some extent some theoretical and numerical investigations have been published regarding the physics of the subject (e.g. Bonnefoy-Claudet et al., 2007). Most of the authors agree that the method is quite reliable in defining the resonance frequency of soft soil over bedrock using ambient noise (e.g. Bard et al., 1997), but should not be considered as safe for the estimatation of the amplification due to seismic excitation by using HVSR curves (Haghshenas et al., 2008). In most cases amplitude measured with ambient noise is considered a low boundary of the actual amplification given by other geophysical and geotechnical methods, like Standard Spectral Ratio (e.g. Maresca et al., 2003). Moreover, the geometry of the sedimentary formation e.g. basin shape, plays an important role to both frequency and amplitude measured with the HVSR technique. When lateral discontinuities are observed, especially at the edges of basin, HVSR peaks appear broader and lower as the slope of basement increases (Cornou et al., 2006)

\subsection{Parametric Numerical Investigation}

To create the source signal for ambient noise recorded in a receiver, we used the RANSOURCE algorithm (Moczo and Kristek, 2002). The algorithm creates random sources either on the surface or in small depth of a given volume. A large number of receivers can be set at the surface or at a depth anywhere in the simulation volume. The time function of the noise sources can be either delta type or pseudo-monochromatic of random length and eigenfrequency, randomly chosen by the algorithm, in an attempt to imitate as much as possible the most common noise sources (impact and pseudo-harmonic).

Hisada (1994, 1995) modified the generalized Transmitter/Receiver coefficient method (Luco and Apsel, 1983), solving the difficulty of calculating Green's function when sources and receivers are located in similar or the same depth. Soil column must be heterogeneous and viscoelastic, horizontally stratified above bedrock, with parameters varying only with depth (1D models). Green functions are calculated for every pair of source-receiver and the time series is the summation of every recording couple. In order for the Green function to be calculated, the 1D geophysical model needs to be provided, consisting of the velocity parameters of the layers for Pand S- waves, thickness and density of layers, and quality factors Qp and Qs.

The volume we chose for creating the noise signal is similar to the size of the Chania basin, namely 2500x2500x10 meters. Receiver is centred on the surface of the volume, with source positions randomly distributed at the surface or down to the depth of $10 \mathrm{~m}$, with an equal contribution (50\%) of delta and pseudo-monochromatic sources. In total 549 sources are created, effecting for 50 seconds. Minimum and maximum simultaneous working sources are set to 1 and 25 , respectively, the minimum distance between sources was 10 meters and the minimum and maximum distance between source and receiver was set to 50 and 2500 meters, respectively. Combining RANSOURCE with Hisada's method produced 50 seconds time series of ambient noise over 1-D model, which by convolution of the time series was increased to 250 seconds.

XLVII. No 3 - 1204 


\section{Results}

\subsection{HVSR Results}

In Figure 1 the HVSR measurements covering most of the extent of the Chania basin are superimposed to the geological map of the study area. In Figure 2 the spatial map of the lower resonance frequency of the area, as defined by the HVSR data, is presented, overlying the geology. Within the area of the city of Chania this fundamental frequency exhibits a peak around $0.4-0.6 \mathrm{~Hz}$ which extends throughout almost to the whole basin. This peak is possibly associated with the impedance contrast between the total column of Quanternary-Neogene sediments and the underlying bedrock formations. At the South, where the mountainous area consisting mainly of marly limestones is located, the peak frequency rises to values ranging 10-18 Hz, corresponding most probably to the superficial cover of soil or weathered bedrock. At the western and southern region of the basin, the peak frequency is lower, ranging between $0.28-0.35 \mathrm{~Hz}$. In Figure 3 the amplitude of the corresponding frequency peak is presented, showing a value between 2-2.5 for the largest part of the urban area, indicating a relatively low impedance between the bedrock and the overlying (mostly Neogene) sediments. In the central part of the basin the observed amplitudes rise to values above 3.7 .

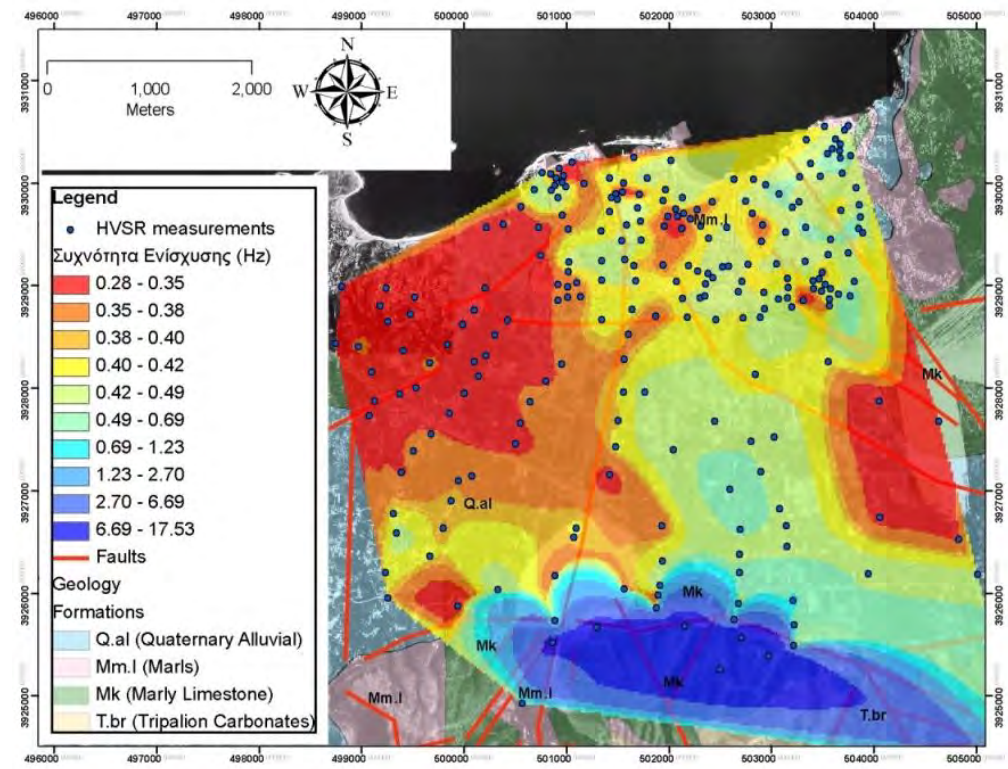

Figure 2 - Spatial distribution of the fundamental frequency defined from HVSR measurements within the broader Chania area.

For many recording sites, especially inside the Quaternary basin of Chania south of the main city complex, a second peak was observed in frequency range of 0.8-4 Hz. Although several research works consider higher frequency HVSR peaks as an indication of higher modes of Rayleigh waves in the ambient noise wavefield, an alternative approach is to consider them as a result of impedance contrast between sediments, corresponding to different layers inside the soft soil formations. In Figure 4 the measurements for which a second frequency peak appears in the HVSR curve are presented along with the spatial map of this higher frequency peak. In the urban area of Chania HVSR measurements appear to have a second peak mostly in the range 3-10 Hz, which can be interpreted as a result of the presence of small lenses of soft Quaternary or Neogene sediments locally placed above stiffer Neogene formations (e.g. stiffer marls). 


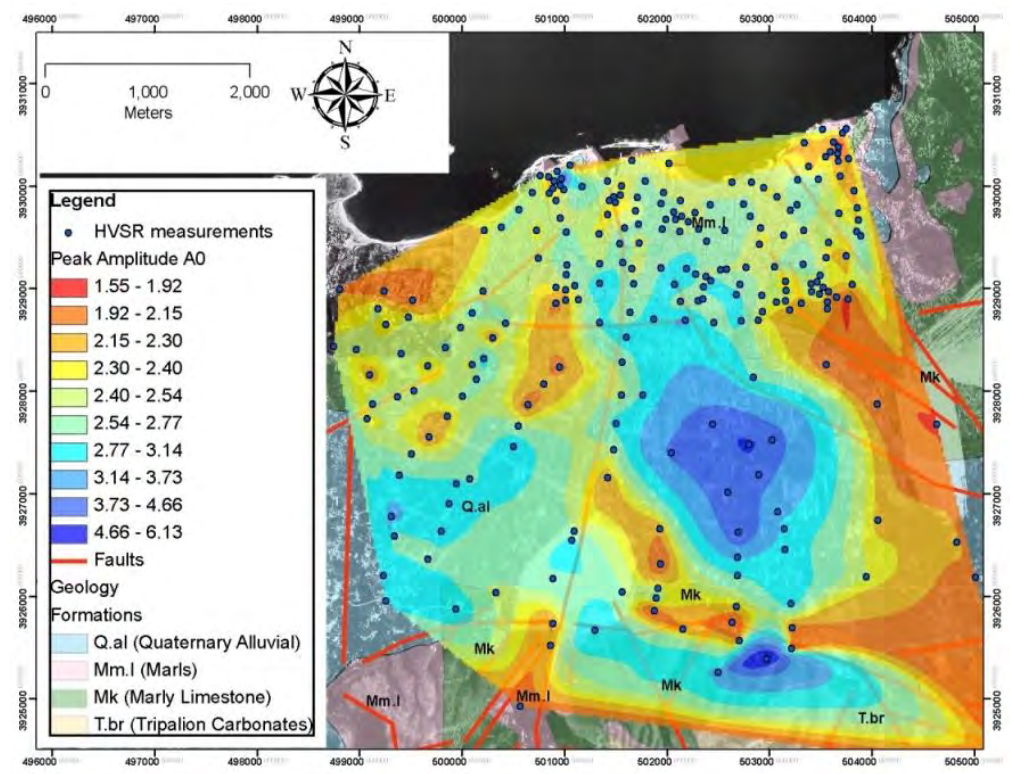

Figure 3 - Spatial distribution of the amplitude of the fundamental frequency peak defined from HVSR measurements within the broader Chania area.

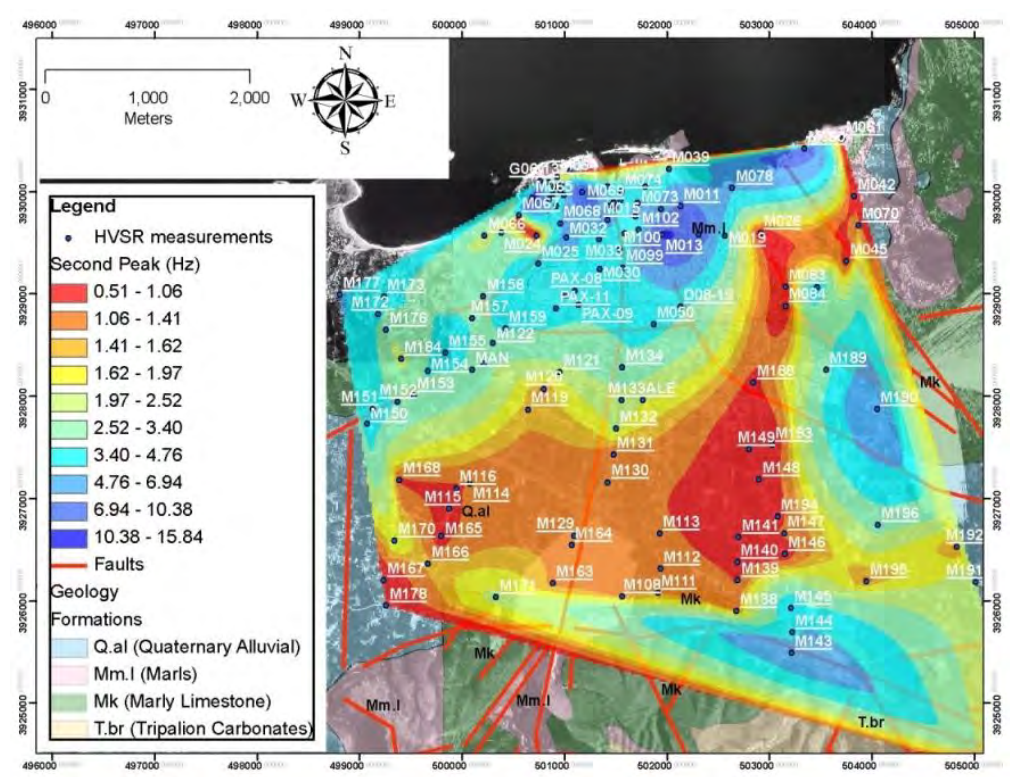

Figure 4 - Spatial distribution of the higher frequency defined from HVSR measurements within the broader Chania area.

Moving to the South, it is evident that the whole basin, which is covered with Quaternary deposits, has a second peak frequency around $1 \mathrm{~Hz}$, which gradually lowers up to $0.5 \mathrm{~Hz}$ towards its centre. We interpret the existence of the second frequency in the basin as related with the impedance ratio between the low velocity Quaternary deposits and the higher velocity Neogene sediments. The difference in frequency between the central section and the basin edges depicts the corresponding difference in thickness of the Quaternary deposits. In Figure 5 the amplitude of the higher frequency peak is presented, showing a maximum again at the centre of the basin, with a value exceeding 3, while at the edges of the basin and in the urban area the value is between 1.8-2.5. 


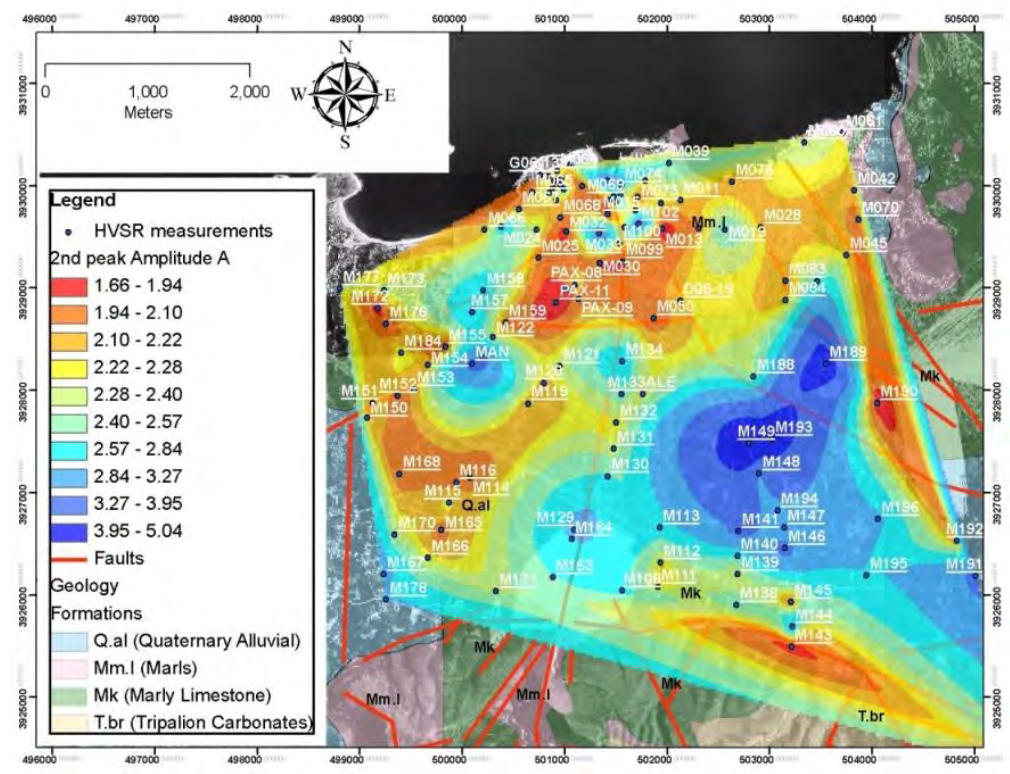

Figure 5-Spatial distribution of the amplitude corresponding to the higher frequency defined from HVSR measurements within the broader Chania area.

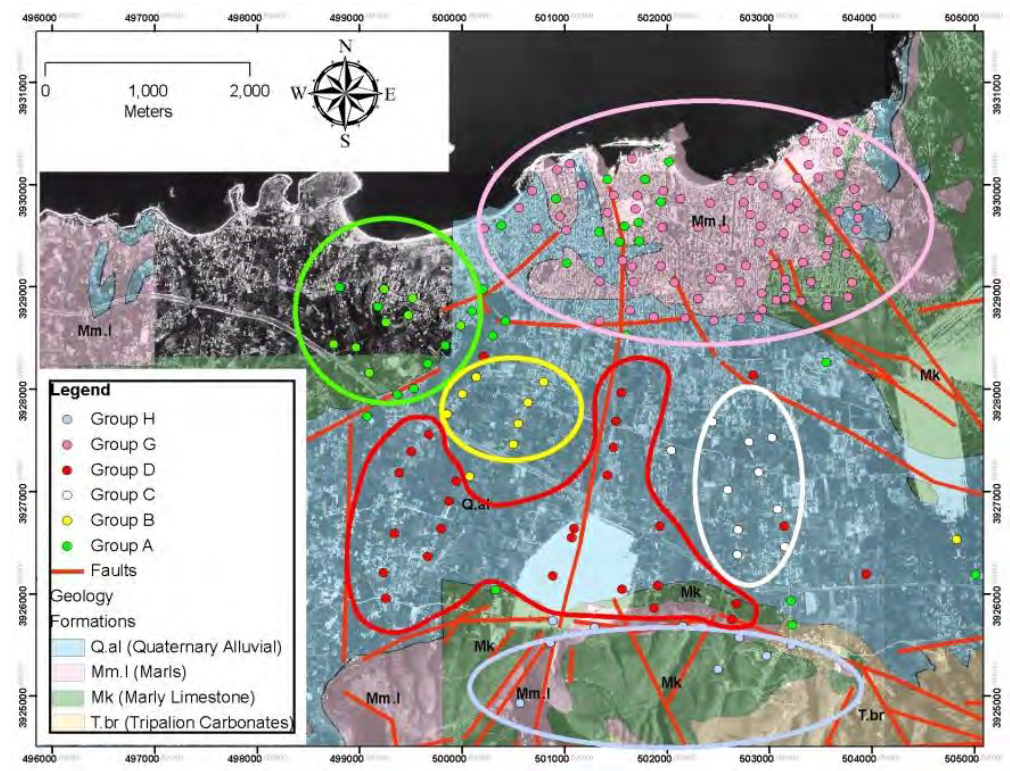

Figure 6 - Spatial grouping of HVSR measurements in the broader Chania area, performed on the basis of the HVSR curve similarity.

\subsection{Parametric Investigation Results}

HVSR curves were correlated on the basis of their similarity into groups, in order to define patterns possibly reflecting the local geological formations. Six (6) groups of HVSR curves have been identified and for each group a parametric investigation was performed using Hisada's method in an attempt to estimate the 1-D model of geological formations for each HVSR group. In Figure 6 the grouping of measurements is presented, showing each area in different colours. Group $\mathrm{H}$ represents all measurements with no significant amplification or amplification in frequencies 
above $12 \mathrm{~Hz}$, mainly identified in the mountainous area at the South, which can be considered as typical for a rock formation. For all other groups, we considered 1-D models for Hisada's calculation of theoretical transfer function. The S-wave velocities employed for these models were derived from independent results (Papadopoulos, 2013), using ambient noise array recordings, which show velocities of the order or $300 \mathrm{~m} / \mathrm{s}$ for Quaternary formations and between 700 (shallower) and 1700m/s (deeper) for Neogene formations (mainly marls), with an average velocity of $\sim 1100 \mathrm{~m} / \mathrm{s}$. Using these velocities as a base for all models, we allowed the Quaternary/Neogene and Neogene/bedrock interfaces to vary, in order to allow the synthetic HVSR curves to match the observed ones. A typical example is presented in Figure (7), where the fit of the synthetic HVSR against observed ones is presented for groups A and G. In general, the modelling allows the efficient simulation of the observed HVSR data, suggesting that their features, especially the higher HVSR frequencies can be efficiently explained by the determined 1D of each sub-area.

The final modelling results are presented in Table 1, showing 2-layer formations in the area covered by the city of Chania (Neogene sediments-bedrock, groups G), and 3-layer geological formations in the basin or the hill area west of the city complex (Quaternary deposits-Neogene sediments-bedrock, groups A, B, C and D). The results show a single clear peak in frequency for Group $\mathrm{H}$, covering the urban area, with a 1D model of Neogene sediments overlying the bedrock. The remaining four models describing the basin geology consist of two layers over bedrock, showing a second peak in frequency that varies, depending on the thickness of the upper layer of mainly Quaternary (locally softer Neogene) deposits. In general the amplitude of a two-peak HVSR curve is low, making the peak identification more difficult; however their presence is still evident, confirming the presence of a velocity contrast between the sedimentary formations (typically Quaternary/Vs $300 \mathrm{~m} / \mathrm{s}$ against stiffer Neogene $/ V_{s} \sim 1100 \mathrm{~m} / \mathrm{s}$ layers).
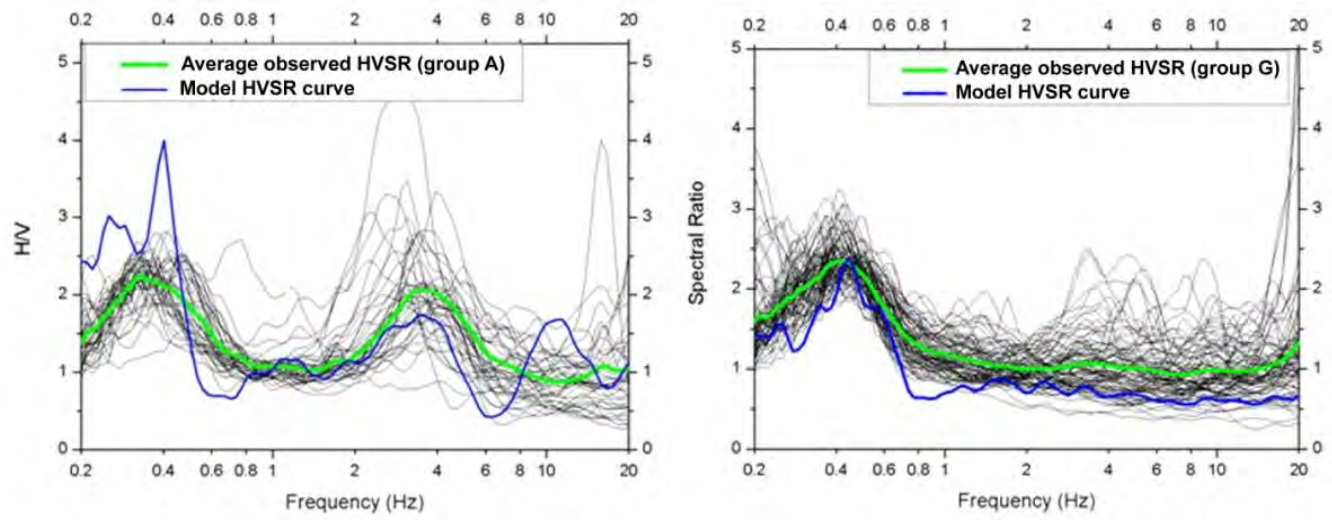

Figure 7 - Theoretical and observed HVSR curves for the spatial HVSR groups A and G, as these are presented in figure 6. Notice the fit of the higher frequency peak for group A, as a result of the presence of shallower low-velocity Quaternary/Neogene formations, and the fit of the fundamental frequency peak $\sim 0.4-0.5 \mathrm{~Hz}$ for both groups (see also Table 1).

\section{Conclusions}

We have studied the complex geological environment of the broader area of the city of Chania, using HVSR measurements that were conducted in order to define the resonance frequency of sediments overlying the bedrock formations (typically Trypalion and Plattenkalk limestones) and estimate the general structure of the main geological formations (Quaternary and Neogene deposits) of the broader area. Results show that for the whole area a peak can be observed in the HVSR curves at a low frequency, around 0.4-0.6 Hz, associated with the velocity contrast between sediments of unknown thickness and the geological/seismic bedrock. A second peak in higher 
frequency appears in the Chania basin, ranging between $0.8-4 \mathrm{~Hz}$, which has been interpreted as the result of the impedance difference between the low velocity Quaternary deposits that cover the basin and the underlying Neogene sediments with higher velocity. Amplitude of the peak frequencies is in the vicinity of 1.5-3.5 for the lower frequency peak and 1.6-2.8 for the higher frequency peak, except for the centre of the basin, where it rises to values of 4-6 and 3-5, respectively.

Simulation of ambient noise confirmed in general the results by calculating the theoretical transfer function using Hisada's method, and providing an estimation of the thickness of the various formations. For all simulations Quaternary deposits have an average velocity of $300 \mathrm{~m} / \mathrm{sec}$, overlying Neogene sediments with velocity around $1100 \mathrm{~m} / \mathrm{sec}$ and bedrock appears with velocity of $3500 \mathrm{~m} / \mathrm{sec}$, as controlled by independent noise array results. Simulation shows that when a two-layer over bedrock model is used, a second peak appears in the HVSR curve, as long as the impedance contrast between the sediments is high enough. At higher frequency (over $6 \mathrm{~Hz}$ ) a third peak appears in the simulation that does not exist at the experimental HVSR curve, which is interpreted as a result of the multiple reflections of the surface waves that is not present in actual HVSR curves, due to model deviations from the 1D structure. The simulation results verify that the higher peak frequency decrease observed for the central part of the Quaternary Chania basin is due to an increase of the thickness of the Quaternary deposits, with group C depicting the higher Quaternary formation thickness of $\sim 100$ m (see Table 1), while other models depict significantly lower estimates (e.g. $20 \mathrm{~m}$ for group A). On the other hand, the Neogene thicknesses vary between 500 and $800 \mathrm{~m}$, verifying the dominant presence of Neogene formations (mainly marls and marly limestones) above bedrock, in excellent agreement with geological observations and models.

Table 1. Geological models used for the simulation of HVSR curves.

\begin{tabular}{|c|c|c|c|c|c|c|c|}
\hline Group & Formation & $\mathrm{Vp}(\mathrm{m} / \mathrm{sec})$ & $\mathrm{Vs}(\mathrm{m} / \mathrm{sec})$ & $\mathrm{H}(\mathrm{m})$ & Qp & Qs & $\rho\left(\mathrm{gr} / \mathrm{cm}^{3}\right)$ \\
\hline \multirow{3}{*}{ A } & Quaternary & 460 & 300 & 20 & 30 & 15 & 1.9 \\
\cline { 2 - 8 } & Neogene & 2000 & 1100 & 800 & 90 & 30 & 2.0 \\
\cline { 2 - 8 } & Bedrock & 5400 & 3500 & - & 300 & 90 & 2.1 \\
\hline \multirow{3}{*}{ B } & Quaternary & 800 & 500 & 80 & 30 & 15 & 1.9 \\
\cline { 2 - 8 } & Neogene & 2500 & 1100 & 800 & 90 & 30 & 2.0 \\
\cline { 2 - 8 } & Bedrock & 5400 & 3500 & - & 300 & 90 & 2.1 \\
\hline \multirow{3}{*}{ C } & Quaternary & 460 & 300 & 100 & 30 & 15 & 1.9 \\
\cline { 2 - 8 } & Neogene & 2100 & 1100 & 500 & 90 & 30 & 2.0 \\
\cline { 2 - 8 } & Bedrock & 5400 & 3500 & - & 300 & 90 & 2.1 \\
\hline \multirow{2}{*}{ D } & Quaternary & 460 & 300 & 60 & 30 & 15 & 1.9 \\
\cline { 2 - 8 } & Neogene & 2000 & 1100 & 800 & 90 & 30 & 2.0 \\
\cline { 2 - 8 } & Bedrock & 5400 & 3500 & - & 300 & 90 & 2.1 \\
\hline \multirow{2}{*}{ G } & Neogene & 2300 & 1400 & 750 & 90 & 30 & 2.0 \\
\cline { 2 - 8 } & Bedrock & 5400 & 3500 & - & 300 & 90 & 2.1 \\
\hline
\end{tabular}

\section{Acknowledgments}

This work has been partly financed by the PYTHAGORAS research project of the Hellenic Ministry of Education (Research Committee of Aristotle University Thessaloniki proj. \#21945\#). 


\section{References}

Bastelli G. 2002. Microzonazione di Chania (Creta), Tesi di laurea, Universita degli Studi della Basilicata (in Italian)

Bard P-Y, Duval AM, Lebrun B, Lachet C, Riepl J and Hatzfeld D. 1997. Reliability of the H/V technique for site effect measurement: an experimental assessment, $17^{\text {th }}$ International conference on soil dynamics and earthquake engineering, Istanbul, 19-24 July 1997.

Bard P.-Y. 1999. Microtremor Measurements: A tool for site effect estimation?, In The Effects of Surface Geology on Seismic Motion, 1251-1279, ed. Irikura, Kudo, Okada and Sasatani, Balkema, Rotterdam.

Bonnefoy-Claudet S., Köhler A., Cornou C., Wathelet M. and Bard P.Y. 2008. Effects of Love waves on microtremor H/V ratio. Bulletin of the Seismological Society of America, 98(1), 288-300.

Cornou C, Guillier B, Kristek J, Bonnefoy-Claudet S, Bard P.Y, Faeh D. and Moczo P. 2006. Simulation of seismic ambient vibrations: does the H/V provide quantitative information in 2D-3D structure, Proceedings of the third international symposium on the effects of surface geology, Grenoble (France), August 30-September 1, 2006, paper \# 153

Field E. and Jacob K. 1995. A comparison of Various Site-Response Estimation Techniques, Including three that are not Reference-Site Dependent, Bull. Seismol. Soc. Am., 85, 11271143.

Haghshenas E., Bard P.Y. and Theodulidis N. 2008. Empirical evaluation of microtremor H/V spectral ratio, Bulletin of Earthquake Engineering, 6(1), 75-108.

Hisada Y. 1994. An efficient method for computing Green's functions for a layered halfspace with sources and receivers at close depths, Bull. Seism. Soc. Am., 84, 5, 1456-1472.

Hisada Y. 1995. An efficient method for computing Green's functions for a layered halfspace with sources and receivers at close depths (Part 2), Bull. Seism. Soc. Am., 85, 4, 1080-1093.

Horike M., Zhao B. and Kawase H.2001. Comparison of site response characteristics inferred from microtremor and earthquake shear waves, Bull. Seism. Soc. Am., 91, 1526-1536.

Konno K., and Ohmachi T. 1998. Ground-motion characteristics estimated from spectral ratio between horizontal and vertical components of microtremor, Bull. Seism. Soc. Am., 88, no. 1, 228-241.

Luco J.E. and Apsel R.J. 1983. On the Green's functions for a layered half-space, part 1, Bull. Seism. Soc. Am . 73, 909-929.

Maresca R., Castellano M., DeMatteis R., Saccorotti G. and Vaccariello P. 2003. Local Site Effects in the town of Benevento (Italy) from Noise Measurements, Pure Appl. Geophys., 160, 1745-1764.

Moczo P. and Kristek J. 2002. FD code to generate noise synthetics, SESAME EVG1-CT-200000026 project, Deliverable D02.09, 31 p, http://SESAME-fp5.obs.ujf-grenoble.fr.

Nakamura Y. 1989. A method for dynamic characteristics estimation of subsurface using ambient noise on the ground surface, QR Railway Tech. Res. Inst., 30, 25-33.

Nogoshi M. and Igarashi T.1970. On the propagation characteristics of microtremors. J. Seism. Soc. Japan, 23, 264-280.

Papadopoulos H. 2013. Experimental and theoretical study of the local site-effect amplification using microtremor recordings and field geophysical measurements, Ph.D. Thesis, Geophysical Laboratory, Aristotle Univ. Thessaloniki, 411pp. 